\title{
OUELLET, Fernand, Papineau. Textes choisis et présentés par Fernand Ouellet, licencié ès-lettres (histoire). "Cahiers de l'Institut d'Histoire Université Laval ». Les Presses \\ Universitaires Laval. Bro. 104 p., grand in-8. Avant-propos de Marcel Trudel. Introduction de l'auteur, 7-11. Chronologie, Notice bibliographique, 12-13. Portrait de Papineau (1832).
}

\section{Lionel Groulx}

Volume 13, numéro 4, mars 1960

URI : https://id.erudit.org/iderudit/302015ar

DOI : https://doi.org/10.7202/302015ar

Aller au sommaire du numéro

Éditeur(s)

Institut d'histoire de l'Amérique française

ISSN

0035-2357 (imprimé)

1492-1383 (numérique)

Découvrir la revue

Citer ce compte rendu

Groulx, L. (1960). Compte rendu de [OUELLET, Fernand, Papineau. Textes choisis et présentés par Fernand Ouellet, licencié ès-lettres (histoire). « Cahiers de l'Institut d'Histoire Université Laval ». Les Presses Universitaires Laval. Bro. 104 p., grand in-8. Avant-propos de Marcel Trudel. Introduction de l'auteur, 7-11. Chronologie, Notice bibliographique, 12-13. Portrait de Papineau (1832).] Revue d'histoire de l'Amérique française, 13(4), 585-586.

https://doi.org/10.7202/302015ar d'utilisation que vous pouvez consulter en ligne. 
OUellet, Fernand, Papineau. Textes choisis et présentés par Fernand Ouellet, licencié ès-lettres (histoire). "Cahiers de l'Institut d'Histoire Université Laval ». Les Presses Universitaires Laval. Bro. 104 pages, grand in-8. Avant-propos de Marcel Trudel. Introduction de l'auteur, 7-11. Chronologie, Notice bibliographique, 12-13. Portrait de Papineau (1832).

Choix de textes opportun. M. Marcel Trudel le note en son Avant-propos: "Jusqu'ici Papineau restait pour ainsi dire inaccessible parce que nulle part ne se trouvaient réunies en un format commode et dans leur ordre naturel les pages capitales de son œuvre.» Le choix de ces textes nous paraît également judicieux. L'auteur nous confie les préoccupations qui l'ont dirigé en ce choix: "Le rôle joué par Papineau, écrit-il, ne peut se comprendre, à notre avis, si on ne l'intègre dans le contexte des conditions économiques, sociales, politiques et religieuses qui existaient au cours de la première moitié du $19^{\mathbf{e}}$ siècle. 》 C'est ce contexte que M. Fernand Ouellet tente d'établir. Les extraits des écrits et discours de Papineau sont assez amples pour rendre justice à la pensée de l'ancien chef. On pourra discuter quelquesunes des notes explicatives de M. Ouellet. L'on en fera de même 
de son «Introduction 》, bon résumé, à tout prendre, de la carrière de Papineau. L'auteur a-t-il toutefois suffisamment dégagé la valable vision et le courage de ce précurseur qui inaugurait, dans un petit coin de son pays, la lutte pour l'avènement à l'autonomie des colonies de l'empire britannique ? On fait aujourd'hui, ce nous semble, trop bon marché de ce mérite, si même l'on ne tient rigueur à Papineau de ne s'être pas tenu pour satisfait du régime parlementaire de 1791 et d'avoir aspiré, pour sa province, à la possession effective du gouvernement. Tout comme si les plus lointains principes du droit constitutionnel britannique ne répugnaient pas essentiellement à l'immobilisme. Les gaucheries ou les faiblesses de ce parlementaire, dans une bataille de près de trente ans, restent, à notre avis, de ces contingences qui ne doivent pas cacher le principal ou l'essentiel.

M. Ouellet nous en avertit loyalement: en ces extraits de Papineau, il a «ajusté la ponctuation », chose permise en édition critique. M. Ouellet ajoute néanmoins qu'il a aussi « apporté certaines corrections afin de rendre les documents plus accessibles ». Excellente intention sans doute. Beaucoup regretteront néanmoins que des notes, au bas des pages, ne nous aient pas indiqué ces corrections, à défaut même de les reproduire. Jusqu'où, en effet, sont allées ces corrections et combien l'auteur s'en est-il permises ? Impossible de ne pas se poser ces questions. Un texte intègre importerait si grandement, au surplus, pour l'étude de la langue parlée ou écrite par Papineau. Et si parfois même l'expression de l'épistolier ou de l'orateur s'est couchée en termes incorrects ou obscurs, serait-il interdit d'y apercevoir le signe vivant des idées ou théories d'un homme dont l'esprit n'a pas toujours échappé à l'imprécision sinon à l'obscurité ?

Ces réserves faites, il reste que la brochure de M. Ouellet est œuvre importante et intelligente. Elle permettra aux étudiants de prendre contact avec une personnalité politique encore fort combattue, mais qui a tenu trop de place en l'histoire canadienne pour qu'on ne lui réserve que du dédain ou qu'on l'expédie cavalièrement aux oubliettes.

LIONEL GROULX, ptre 